\title{
Improved Resistance to Root-knot Nematode Species in an Advanced Inbred Line of Specialty Pepper (Capsicum annuum)
}

\author{
Mary Ann D. Maquilan \\ Entomology and Nematology Department, University of Florida, 1881 \\ Natural Area Drive, Gainesville, FL 32611
}

\author{
Dominick C. Padilla \\ Horticultural Sciences Department, University of Florida, 2550 Hull Road, \\ Gainesville, FL 32611
}

\author{
Donald W. Dickson \\ Entomology and Nematology Department, University of Florida, 1881 \\ Natural Area Drive, Gainesville, FL 32611
}

\section{Bala Rathinasabapathi \\ Horticultural Sciences Department, University of Florida, 2550 Hull Road, Gainesville, FL 32611}

\begin{abstract}
Additional index words. Capsicum chinense, disease, genetic resistance, plant-nematode interaction, reproduction factor, root-knot nematode management, sweet pepper
\end{abstract}

\begin{abstract}
Bell and chili peppers are important vegetable and spice commodities worldwide. Significant yield reductions have been attributed to damage caused by root-knot nematodes (RKNs; Meloidogyne spp.). This study addresses the need for developing pepper varieties that have high resistance to $R K N$, which is now of increasing importance due to restrictions on the use of fumigant nematicides. Our goal is to provide a nonchemical alternative to sustain commercial pepper production in Florida, which is a major producer of peppers in the United States. We evaluated 'UFRJ107(6)A3', an advanced inbred line developed from a cross between Capsicum annuum L. 'Jalapeno' and 'Round of Hungary', for resistance against the nematode in comparison with the parental and three other Capsicum cultivars, namely, $C$. annuum 'Charleston Belle', 'California Wonder', and $C$. chinense Jacq. 'Datil' in two separate growth chamber experiments. Based on egg mass indices and reproduction factors, 'UFRJ107(6)A3' was significantly more resistant to $M$. incognita compared with the other five cultivars. When tested with five RKN species, 'UFRJ107(6)A3' showed comparably high levels of resistance to $M$. arenaria and $M$. floridensis as 'California Wonder' based on the nematode reproduction factor. In 'UFRJ107(6)A3', however, there were no detectable $M$. arenaria egg masses, and $M$. incognita reproduction was minimal compared with that of 'California Wonder'; both cultivars supported the reproduction of M. enterolobii and $M$. javanica, although the reproduction factors of $M$. enterolobii were $\approx 10$-fold higher than $M$. javanica. To characterize the mechanism of high resistance to $M$. incognita in 'UFRJ107(6)A3', we examined the extent to which infective second-stage juveniles (J2s) were able to penetrate its roots in comparison with the susceptible 'California Wonder' and 'Datil' in two independent experiments; we conducted RKN root penetration assays with a single plant in a pot and two plants in a single-pot choice test using 'Datil' and 'California Wonder', respectively, as susceptible standards. In both assays, $M$. incognita J2s were absent in the roots of ' $U F R J 107(6) A 3$ ' 7 days after inoculation but were present in the susceptible cultivars, indicating that resistance has an effect at the root invasion stage. In growth chamber experiments, at constant temperatures of 28 and $30{ }^{\circ} \mathrm{C}$, 'UFRJ107(6)A3' exhibited $M$. incognita resistance superior to its parents and to the standard resistant bell pepper 'Charleston Belle', thus offering the potential to enhance specialty pepper production and for use as a nematode-resistant rootstock for commercial bell peppers.
\end{abstract}

Plant-parasitic root-knot nematodes (RKNs; Meloidogyne spp.) can cause severe damage to their hosts, leading to reductions in crop yield and quality (Taylor and Sasser, 1978). These pathogens become problematic, especially in warmer weather in summer and fall. Because they thrive in warm, moist soils that occur in plasticulture systems for the production of high-value vegetable crops such as tomato and pepper, soil fumigation is considered an essential component in such intensive vegetable cropping systems. Flor- ida is a major producer of peppers in the United States; in 2018, the quantity of harvested bell peppers valued at $\$ 180.6$ million was from $30 \%$ of the total harvested area in the nation (USDA-NASS, 2018). Nationwide phasing out of methyl bromide, the effective preplant broad-spectrum fumigant, has created a challenge for protecting the bell pepper crop in Florida (Biswas et al., 2017). Although chemical alternatives to methyl bromide are available, their efficacy is cropspecific, and they can be phytotoxic to certain crops (Morris et al., 2016; Oka et al., 2012). Nonchemical alternatives such as nematoderesistant cultivars are proposed as a potential long-term solution for managing RKNs in vegetable cropping systems (Civerolo et al., 1993).

Resistance of peppers (Capsicum annuum) to $M$. incognita was demonstrated to be conditioned by a single dominant gene, designated as the $N$ gene, through resistance testing of selected progenies of M. incognitaresistant 'Santanka $\mathrm{xS}^{\prime}$ ' and those of equally resistant '405B Mexico'. The parental cultivars and their $\mathrm{F}_{3}$ progenies also showed resistance to $M$. arenaria and $M$. javanica (root-knot indices of zero); therefore, it was posited that the $N$ gene confers resistance to the three RKN species (Hare, 1957). The first nematode-resistant bell pepper cultivar Charleston Belle, released by the USDAARS in 1997, is homozygous for the $N$ gene, and its resistance to RKN was inherited from 'Mississippi Nemaheart', which is the same donor parent of the resistant cultivar Carolina Wonder. 'Charleston Belle' exhibited high levels of resistance to $M$. incognita in the field (Fery et al., 1998); subsequently, it was also found to be resistant to $M$. arenaria and $M$. javanica, respectively, under growth chamber $\left(27{ }^{\circ} \mathrm{C}\right)$ and greenhouse $(26 \pm$ $3{ }^{\circ} \mathrm{C}$ ) conditions (Thies and Fery, 2000). 'Charleston Belle' and 'Carolina Wonder' both showed minimum root galling and nematode reproduction of $M$. incognita when evaluated under Florida's subtropical environment, with soil temperatures ranging from 17 to $37^{\circ} \mathrm{C}$ in spring and 20 to $36^{\circ} \mathrm{C}$ in fall (Thies et al., 2008). Other sources of resistance to $M$. incognita have been found in some Scotch Bonnet (C. chinense) cultigens (Fery and Thies, 1997), and their efficacy in managing RKNs in subtropical conditions has been demonstrated (Thies et al., 1998; Thies and Fery, 2002). However, it has been reported that the $N$ gene in resistant genotypes of $C$. annuum and $C$. chinense was not effective against an isolate of $M$. incognita originating from a commercial bell pepper field in California (Fery et al., 1998; Thies, 2011). Furthermore, the $M e 3$ gene, which confers resistance to $M$. incognita, $M$. arenaria, and $M$. javanica, in resistant doubled haploid $C$. annuum line 'HDA149' was not effective against some isolates of $M$. arenaria and $M$. incognita (Castagnone-Sereno et al., 2001). Natural variation exists among $M$. incognita populations, and the potential for these to infect $\mathrm{Me} 3$ - and $\mathrm{N}$-gene-carrying pepper genotypes (Bucki et al., 2017) 
compounds the problem of the lack of an effective fumigant in pepper production systems. Hence, there is a need to continue to develop new germplasm lines with improved resistance to $M$. incognita as well as broad resistance to RKN.

The isogenic $C$. annuum lines developed in France carry dominant RKN resistance genes, Mel and $\mathrm{Me3}$, which confer heatstable and broad-spectrum resistance (Djian-Caporalino et al., 1999; Hajihassani et al., 2019; Hendy et al., 1985). Infection of second-stage juveniles (J2s) from different Meloidogyne spp. elicited variable responses in the resistant lines either by a reduction in nematode penetration or by necrosis of epidermal and cortical cells involved in nematode penetration and feeding (Bleve-Zacheo et al., 1998; Pegard et al., 2005).

Breeding peppers that enhance and broaden resistance against RKNs will help to decrease grower dependence on chemical nematicides. In our pepper breeding program, we have developed an inbred line of specialty pepper 'UFRJ107(6)A3' derived from crossing 'Jalapeño' chili pepper with an heirloom sweet pepper (Wang et al., 2018). This breeding line was selected for its outstanding horticultural features as a specialty pepper and showed good adaptation in replicated performance trials under Florida's subtropical climate. We evaluated the level of resistance in 'UFRJ107(6)A3' against three main RKNs (M. incognita race 3 , M. arenaria, and $M$. javanica) and two emergent nematodes in Florida (M. floridensis and M. enterolobii) based on penetration, reproduction, and host preference of the nematodes in a controlled environment. Five other cultivars with varying degrees of resistance were tested for comparative information.

\section{Materials and Methods}

Inoculum preparation. Single egg mass isolates of $M$. incognita race $3, M$. arenaria, $M$. javanica, M. floridensis, and M. enterolobii were obtained from the Entomology and Nematology Department, University of Florida. The identity of each species was confirmed via esterase and malate dehydrogenase enzyme profiles (Dickson, et al., 1971) and host differential tests (Taylor and Sasser, 1978). All Meloidogyne spp. were

Received for publication 12 Feb. 2020. Accepted for publication 7 May 2020.

Published online 4 June 2020.

This research was funded by the U.S. Department of Agriculture's Agricultural Marketing Service and the Florida Department of Agriculture and Consumer Services (USDA_AMS-SCBGP-2018, UF Project 76748). Its contents are solely the responsibility of the authors and do not necessarily represent the official views of the USDA or FDACS.

M.D.M. and D.C.P. have equally contributed to this work.

B.R. is the corresponding author.

E-mail: brath@ufl.edu.

This is an open access article distributed under the CC BY-NC-ND license (https://creativecommons.org/ licenses/by-nc-nd/4.0/). increased on tomato (Solanum lycopersicum L. cv. BHN 589) and maintained in the greenhouse at $25 \pm 5^{\circ} \mathrm{C}$. Eggs were extracted from the infected tomato roots by dissolving the gelatinous egg sacs with $0.25 \%(\mathrm{w} / \mathrm{v})$ sodium hypochlorite solution (Hussey and Barker, 1973), and eggs were captured on a sieve with $25-\mu \mathrm{m}$-pore openings. The eggs were allowed to hatch at room temperature using a modified Baermann technique with the eggs placed on a wire mesh lined with moistened tissue paper inside a petri dish. Only 24-h-old J2s were used for the experiments.

Pepper genotypes. Seeds of 'California Wonder' bell pepper, 'Round of Hungary' sweet pepper, and 'Jalapeño' chili pepper were purchased from Park Seeds (Greenwood, SC), and 'Charleston Belle' bell pepper and 'Datil' chili pepper were purchased from Baker Creek Heirloom Seeds (Mansfield, MO). 'California Wonder' is a known susceptible variety (Thies et al., 1998). Resistance to $M$. incognita is relatively welldescribed in 'Charleston Belle' (Fery et al., 1998), whereas resistances in 'Round of Hungary', 'Jalapeño', and 'Datil' —a hot pepper variety commercially grown predominantly in Saint Augustine, FL-have not been formally tested. The advanced inbred line 'UFRJ107(6)A3' originated from the controlled crossing of 'Round of Hungary' with pollen from 'Jalapeno' (Fig. 1). 'UFRJ107(6)A3' is an $F_{7}$ breeding line derived from an $\mathrm{F}_{2}$ plant grown in the greenhouse and selected based on broad-mite tolerance. Superior $\mathrm{F}_{3}$ lines selected for their general field performance and fruit quality were advanced through $\mathrm{F}_{7}$. Therefore, the pedigree of 'UFRJ107(6)A3' combines the desirable characteristics of 'Jalapeño' (for pungency) and 'Round of Hungary' (for fruit color, high brix, and fleshy pericarp), as well as novel traits resulting from selections including broad-mite tolerance and adaptability to subtropical climate.

Preparation of plant materials. Seeds were surface-treated with $10 \%(\mathrm{v} / \mathrm{v})$ commercial bleach for $20 \mathrm{~min}$, rinsed with sterile water five times, and allowed to germinate in a $125-\mathrm{mL}$ erlenmeyer flask containing $25 \mathrm{~mL}$ $0.1 \%(\mathrm{w} / \mathrm{v})$ potassium nitrate solution. The flask was incubated on an orbital shaker $(80$ $\mathrm{rpm}$ at $\left.28{ }^{\circ} \mathrm{C}\right)$. The germinated seeds were planted in 128-cell plug trays with autoclaved $\left(121{ }^{\circ} \mathrm{C}\right.$ for $30 \mathrm{~min}$ ) peat-based soil mix (Fafard 3B; Sun Gro Horticulture, Agawam, MA). Each plant was watered daily with 50 $\mathrm{mL}$ water and fertilized every 3 weeks with $50 \mathrm{~mL} 0.21 \%(\mathrm{w} / \mathrm{v})$ fertilizer solution $(24 \mathrm{~N}-$ 8P-16K, Miracle-Gro; Scotts Miracle-Gro Products, Inc., Marysville, $\mathrm{OH})$. The plants were maintained on lighted shelves at $25 \pm$ $2{ }^{\circ} \mathrm{C}$ for 8 weeks before they were transferred to environmental growth chambers. Four- to five-leaf-stage seedlings were transplanted individually, unless otherwise mentioned, to autoclaved all-purpose sand (Quikrete, Atlanta, GA) contained in 251-mL Styrofoam cups with needle-punched drainage holes in the bottom.
Growth chamber conditions. Experiments to assess reproduction, root penetration, and host preference of RKN were performed in plant growth chambers (Percival Scientific, Perry, IA) set at a constant temperature of $28^{\circ} \mathrm{C}$ or $30^{\circ} \mathrm{C}$ with a 12 -h photoperiod $(150$ $\mu \mathrm{mol} \cdot \mathrm{m}^{-2} \cdot \mathrm{s}^{-1}$ provided by fluorescent lamps). Plants were watered and fertilized as described.

Assessment of nematode reproduction. The nematode inocula (24-h-old J2s) were pipetted into three holes (depth, $3 \mathrm{~cm}$ ) made in the soil around the plant base. During the first growth chamber experiment at $28^{\circ} \mathrm{C}$ that examined $M$. incognita resistance in five pepper genotypes, the applied inoculum of freshly hatched J2 ranged from 60 to 240 ; the level of inoculum was adjusted based on the plant size variation. During subsequent growth chamber experiments at $30{ }^{\circ} \mathrm{C}$ and tests with five RKN species ( $M$. incognita, $M$. arenaria, $M$. javanica, $M$. enterolobii, and $M$. floridensis), the level of nematode inoculum was $240 \mathrm{~J} 2 \mathrm{~s}$ per pot. Five plants of each pepper genotype were maintained in the growth chamber for $30 \mathrm{~d}$; after which, the plants were removed from containers and the roots were washed gently with running water to remove sand particles. Root fresh weights were recorded to estimate the number of egg masses and eggs per gram of root before soaking the roots in red food color (McCormick and Co. Inc., Hunt Valley, MD) to aid with the observation of egg masses (Thies et al., 2002). Nematode reproduction was assessed by counting the stained egg masses. No data were collected for plants that were damaged by wilt disease during the course of the experiment. The stained egg masses on roots were counted under the stereomicroscope equipped with an overhead illuminator. Each plant was rated based on the number of egg masses using a scale of 0 to 5: $0=$ no egg mass; $1=1$ to 2 egg masses per whole root system; $2=3$ to 10 egg masses; $3=11$ to $30 ; 4=31$ to 100 ; and $5=$ more than 100 (Taylor and Sasser 1978). After counting the egg masses, eggs were extracted from whole root systems using the sodiumhypochlorite method (Hussey and Barker, 1973). Nematode reproduction was measured by calculating the reproduction factor $(\mathrm{RF}=$ ratio of the number of nematode eggs at $30 \mathrm{~d}$ postinoculation to the initial number of $\mathrm{J} 2 \mathrm{~s}$ with which the plants were inoculated). Egg and egg mass densities, expressed as number per gram of fresh root to account for variations in the size of roots from different pepper genotypes, were also compared.

Root penetration of $M$. incognita race 3 . Pepper seeds were germinated and seedlings were maintained as mentioned. At transplanting, $500 \mathrm{~J} 2 \mathrm{~s}$ suspended in $3 \mathrm{~mL}$ water were pipetted into three holes (3-cm deep) made in the soil around the plant base. Six replicates each of 'Datil' and 'UFRJ107(6)A' were maintained in a growth chamber at $30{ }^{\circ} \mathrm{C}$ with a 12-h photoperiod. At $7 \mathrm{~d}$ after inoculation, plants were removed from containers and washed gently with running water to remove soil particles. Roots were soaked in 


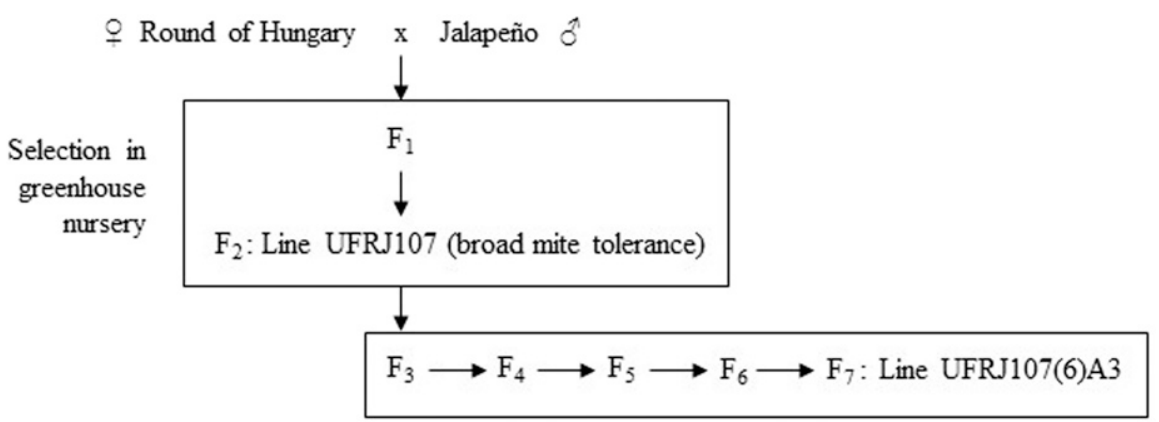

Lines were advanced based on field performance and fruit quality.

Fig. 1. Development of the root-knot nematode-resistant specialty pepper advanced breeding line 'UFRJ107(6)A3' via single-seed descent.

$1.5 \%$ sodium hypochlorite solution for $2 \mathrm{~min}$ and stained with acid fuchsin (Byrd et al., 1983 ) before examination under a stereomicroscope.

Single-pot choice test. In the growth chamber set at $30{ }^{\circ} \mathrm{C}, 500 \mathrm{M}$. incognita race $3 \mathrm{~J} 2 \mathrm{~s}$ were inoculated in each pot containing two plants. Each plant in the pot was inoculated with $250 \mathrm{~J} 2 \mathrm{~s}$ suspended in $3 \mathrm{~mL}$ water and distributed to three holes around the stem base of each plant, for a total of $6 \mathrm{~mL}(500$ $\mathrm{J} 2 \mathrm{~s}$ ) per pot when two plants were grown in the same container. In this experiment, a total of 12 plants were distributed to the following treatments, each with two replicate pots: 1) two 'California Wonder' plants per pot; 2) two 'UFRJ107(6)A3' plants per pot; and 3) one plant of each genotype together in the same pot. The preference of RKN was evaluated at $7 \mathrm{~d}$ after inoculation by root-staining with acid fuchsin (Byrd et al., 1983) and examining root tissues under a stereomicroscope for the presence of $\mathrm{J} 2 \mathrm{~s}$.

Statistical treatment of data. During all experiments, a completely randomized design was used. Quantitative data were used to calculate means and the SE. Data were normalized using the square-root $(x+1)$ transformation for RF and egg mass index and log $(\mathrm{x}+1)$ transformation for egg or egg mass numbers per gram of root before being subjected to one-way analysis of variance (ANOVA) using the SAS statistical package (SAS Institute, Cary, NC). For nematode reproduction parameters that differed significantly $(P \leq 0.05)$ based on the ANOVA, Tukey's honestly significant difference test $(P \leq 0.05)$ was used to compare means across pepper genotypes. The statistical significance of the difference in nematode root penetration between two genotypes was tested using Student's $t$ test $(P \leq 0.05)$.

\section{Results and Discussion}

We used multiple methods to characterize RKN resistance of pepper using an inbred line developed by our program and several commercially available varieties. Because the nematode reproductive ability in a host is directly related to the host's resistance (Taylor and Sasser, 1978), the egg mass index and RF were used as key parameters to assess the level of nematode resistance in 'Datil', 'Round of Hungary', 'Jalapeño', and 'UFRJ107(6)A3', along with known resistant ('Charleston Belle') and susceptible ('California Wonder') cultivars. The RKN penetration in host roots and resistance to multiple species of Meloidogyne were performed to gain a better understanding of the nature and spectrum of resistance in 'UFRJ107(6)A3'.

The reproductive potential of $M$. incognita race 3 was affected by the genotype of its host (Table 1). At $28^{\circ} \mathrm{C}$, the mean egg masses per gram of root ranged from 0.2 to 58 , with 'California Wonder' and 'Datil' being most susceptible, 'Charleston Belle' being moderately susceptible, and 'Jalapeno' and 'UFRJ107(6)A3' being highly resistant. The RFs reflected these gradations in $M$. incognita resistance, with the highest mean RF for 'California Wonder', followed by 'Datil', 'Charleston Belle', 'Jalapeño', and 'UFRJ107(6) A3' in decreasing order.

The trial was repeated at $30{ }^{\circ} \mathrm{C}$ and included 'Round of Hungary', which is a parental variety of 'UFRJ107(6)A3' (Fig. 1, Table 1). The mean egg masses per gram of root ranged from 0.3 to 62 , with the highest value in 'Round of Hungary', followed by 'Charleston Belle', 'California Wonder', 'Jalapeño', and 'UFRJ107(6)A3' (Table 1) in decreasing order. Mean RF values followed the same order of ranking as mean egg masses per gram of root (Table 1). Although a full replication of 'Datil' was not included in the experiment at $30^{\circ} \mathrm{C}$, two plants that were inoculated were highly susceptible to $M$. incognita (data not shown). 'Datil' did not exhibit the high levels of $M$. incognita resistance found in some Scotch Bonnet-type peppers, thereby reflecting the intraspecific variability of $M$. incognita resistance in $C$. chinense (Fery and Thies, 1997; Gisbert et al., 2013).

The resistance responses of 'UFRJ107(6) A3' from the two growth chamber experiments at constant temperatures of 28 and $30{ }^{\circ} \mathrm{C}$ were in good agreement, suggesting stability of its resistance at a higher temperature. 'UFRJ107(6)A3' was highly resistant to $M$. incognita in both trials (egg mass index and $\mathrm{RF}<1$ ) (Table 1). Because the mean RF value for 'Jalapeño' was less than that of 'Round of Hungary', we surmised that 'UFRJ107(6)A3' may have inherited $M$. incognita resistance from the 'Jalapeño' parent. Nematode reproduction in 'UFRJ107(6)A3' was minimal and less than that of its 'Jalapeño' parent; hence, additional genetic factors may be involved in the resistance of 'UFRJ107(6)A3', which is not uncommon in $C$. annuum (Fery and Dukes, 1996).

The susceptibility of 'California Wonder' to $M$. incognita race 3 in this study confirmed previous observations by Thies et al. (1998). 'Charleston Belle', homozygous for the $N$ gene, was reported to be resistant to $M$. incognita race 3 under field and greenhouse conditions (Fery et al., 1998; Hajihassani et al., 2019); however, under the conditions used in the present study, this cultivar was susceptible $(\mathrm{RF}=24)$ when compared with 'UFRJ107(6)A3' $(\mathrm{RF}=0.2-0.8)($ Table 1$)$. Results have been inconsistent with regard to resistance in 'Charleston Belle' during field, growth chamber, and greenhouse tests. Thies and Fery (1998) reported that the expression of $N$ gene is modified at high temperatures (28 and $32{ }^{\circ} \mathrm{C}$ ) and further confirmed partial loss of resistance (based on eggs per gram of fresh root and reproductive index) conferred by the $N$ gene in $C$. annuum and an allelic gene in $C$. chinense at these higher temperatures in growth chambers (Thies and Fery, 2000). However, in field trials set in a subtropical environment with soil temperatures ranging widely from 17 to $37{ }^{\circ} \mathrm{C}$ in spring and 20 to $36^{\circ} \mathrm{C}$ in fall, minimal galling (less than $3 \%$ root system galled) on 'Charleston Belle' was observed (Thies, et al., 2008). Under greenhouse conditions, Aguiar et al. (2014) observed higher infestation levels of $M$. incognita $\mathrm{J} 2$ in 'Charleston Belle' than in 'Carolina Wonder', which is also homozygous for the $N$ gene, after 3 months from inoculation. Although we do not know the underlying cause for the instability of resistance in 'Charleston Belle', the different results obtained in the present study may be related to the assay conditions, including seedling age, evaluation period, continuous exposure to high temperatures in the growth chamber, and the nature of the nematode population used.

We compared 'UFRJ107(6)A3' with 'California Wonder' to determine resistance to five different species of Meloidogyne using similar bioassays at $28{ }^{\circ} \mathrm{C}$, as described. Based on egg masses per gram of root, eggs per gram of root, egg mass index, and RF, 'California Wonder' was highly susceptible to $M$. incognita race 3, whereas 'UFRJ107(6) A3' was resistant (Table 2). Both genotypes were resistant to $M$. arenaria and $M$. floridensis but susceptible to $M$. enterolobii and M. javanica (Table 2). The RF of Meloidogyne enterolobii was $\approx 10$-fold higher than that of $M$. javanica on both genotypes. Meloidogyne arenaria failed to reproduce on 'UFRJ107(6)A3', as did M. floridensis 
Table 1. Reproductive potential of Meloidogyne incognita race 3 on six varieties of Capsicum species after $30 \mathrm{~d}$ from inoculation under two temperature regimes in the growth chamber.

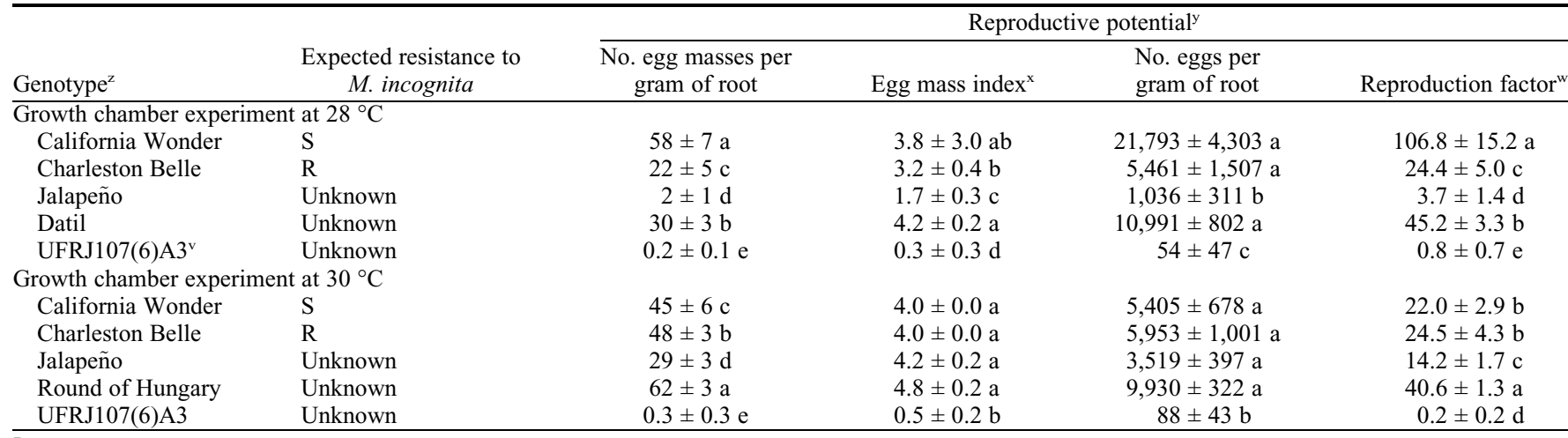

${ }^{\mathrm{z}}$ Four- to five-leaf-stage pepper seedlings were transplanted to autoclaved sand and incubated in growth chambers set at either $28{ }^{\circ} \mathrm{C}$ or $30{ }^{\circ} \mathrm{C}$ with a $12-\mathrm{h}$ photoperiod. After 1 week from transplanting, each plant was inoculated with 60-240 24-h-old second-stage juveniles (J2s) for the growth chamber experiment at $28^{\circ} \mathrm{C}$ and 240 24-h-old $\mathrm{J} 2 \mathrm{~s}$ for the experiment at $30^{\circ} \mathrm{C}$.

${ }^{\mathrm{y}}$ Data were normalized using the square root $(\mathrm{x}+1)$ transformation for reproduction factor and egg mass index, and the log $(\mathrm{x}+1)$ transformation for egg or egg mass numbers per gram of root. Nontransformed means $\pm \mathrm{SE}(\mathrm{n}=3-5)$ are shown. Means followed by the same letter within a column are not different at $P \leq 0.05$ using Tukey's honestly significant difference test.

${ }^{\mathrm{x}}$ Rating scale: 0 to $5: 0=$ no egg masses; $1=1$ to 2 egg masses per whole root system; $2=3$ to $10 ; 3=11$ to $30 ; 4=31$ to 100 ; and $5=$ more than 100 (Taylor and Sasser, 1978).

${ }^{\mathrm{w}}$ Reproduction factor $=$ the ratio of the number of nematode eggs at $30 \mathrm{~d}$ postinoculation to the initial number of J2s with which the plants were inoculated.

${ }^{\mathrm{v}}$ 'UFRJ107(6)A3' is a $\mathrm{F}_{7}$ breeding line with the combined features of parent cultivars Jalapeño (for pungency) and Round of Hungary (for fruit color, high brix, and fleshy pericarp), as well as novel traits resulting from selections including broad-mite tolerance and adaptability to subtropical climate.

Table 2. Degree of resistance in Capsicum annuum 'UFRJ107(6)A3' to five Meloidogyne species in comparison with M. incognita-susceptible cultivar California Wonder after $30 \mathrm{~d}$ from inoculation.

\begin{tabular}{|c|c|c|c|c|c|c|}
\hline \multirow[b]{2}{*}{ Parameters for resistance $\mathrm{z}$} & \multirow[b]{2}{*}{ Genotype $^{y}$} & \multicolumn{5}{|c|}{ Meloidogyne species } \\
\hline & & M. arenaria & M. incognita race 3 & M. enterolobii & M. floridensis & M. javanica \\
\hline \multirow[t]{2}{*}{ No. of egg masses per gram of root } & California Wonder & $8 \pm 6$ & $163 \pm 33$ & $252 \pm 26$ & $0 \pm 0$ & $1 \pm 1$ \\
\hline & UFRJ107(6)A3 ${ }^{x}$ & $0 \pm 0$ & $0 \pm 0$ & $269 \pm 58$ & $0 \pm 0$ & $1 \pm 0$ \\
\hline \multirow[t]{2}{*}{ Egg mass index ${ }^{w}$} & California Wonder & $0.8 \pm 0.6$ & $5.0 \pm 0$ & $5.0 \pm 0$ & $0 \pm 0$ & $1.3 \pm 0.3$ \\
\hline & UFRJ107(6)A3 & $0 \pm 0$ & $0.3 \pm 0.2$ & $5.0 \pm 0$ & $0 \pm 0$ & $0.8 \pm 0.6$ \\
\hline No. of eggs per gram of root & California Wonder & $154 \pm 133$ & $11,898 \pm 1,392$ & $16,259 \pm 2,695$ & $0 \pm 0$ & $837 \pm 740$ \\
\hline \multirow[t]{2}{*}{ Reproduction factor ${ }^{v}$} & California Wonder & $0.3 \pm 0.2$ & $56.0 \pm 9.6$ & $51.8 \pm 4.5$ & $0 \pm 0$ & $5.0 \pm 3.3$ \\
\hline & UFRJ107(6)A3 & $0 \pm 0$ & $2.8 \pm 2.4$ & $60.5 \pm 12.6$ & $0 \pm 0$ & $7.0 \pm 3.5$ \\
\hline
\end{tabular}

${ }^{\mathrm{z}}$ Data represent means $\pm \mathrm{SE}$ of five replicates.

${ }^{\mathrm{y}}$ Four- to five-leaf-stage pepper seedlings were transplanted to autoclaved sand and incubated in a growth chamber set at $28^{\circ} \mathrm{C}$ with a 12 -h photoperiod. After 1 week from transplanting, each plant was inoculated with 240 24-h-old second-stage juveniles (J2s).

${ }^{\mathrm{x}}$ 'UFRJ107(6)A3' is a $\mathrm{F}_{7}$ breeding line with the combined features of parent cultivars Jalapeño (for pungency) and Round of Hungary (for fruit color, high brix, and fleshy pericarp), as well as novel traits resulting from selections including broad-mite tolerance and adaptability to subtropical climate.

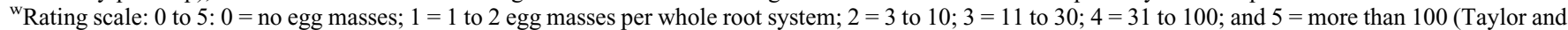
Sasser, 1978).

${ }^{\mathrm{v}}$ Reproduction factor $=$ the ratio of the number of nematode eggs at $30 \mathrm{~d}$ postinoculation to the initial number of juveniles with which the plants were inoculated.

Table 3. Number of $M$. incognita race 3 second-stage juveniles (J2s) observed in roots of Capsicum annuum 'UFRJ107(6)A3' and C. chinense 'Datil' peppers after $7 \mathrm{~d}$ from inoculation with $500 \mathrm{~J} 2 \mathrm{~s}$.

\begin{tabular}{|c|c|}
\hline Genotype $^{z}$ & Number of $\mathrm{J} 2$ in roots \\
\hline Datil & $102 \pm 12$ \\
\hline UFRJ107(6)A3 ${ }^{x}$ & $0 \pm 0$ \\
\hline $\begin{array}{l}{ }^{\mathrm{Z}} \text { Four- to five-leaf } \\
\text { chamber set at } 30{ }^{\circ} \\
\text { with } 50024-\mathrm{h}-\mathrm{old} \\
{ }^{\mathrm{y} D a t a} \text { represent m } \\
{ }^{\mathrm{x}} \text { 'UFRJ107(6)A3' } \\
\text { pungency) and Ro } \\
\text { resulting from sele }\end{array}$ & $\begin{array}{l}\text { and incubated in growth } \\
\text { each plant was inoculated } \\
\text { t cultivars Jalapeño (for } \\
\text { o), as well as novel traits } \\
\text { tropical climate. }\end{array}$ \\
\hline
\end{tabular}

on both 'UFRJ107(6)A3' and 'California Wonder' (Table 2).

Although the 'UFRJ107(6)A3' line has shown resistance to four root-knot nematode species $M$. incognita, M. javanica, M. arenaria, and $M$. floridensis, additional sources of resistance to $M$. enterolobii are needed because this species has become highly pathogenic to economically important crops. It has been reported that $M$. enterolobii is able to overcome resistance conferred by the Mi-1 gene in tomato and $N$ gene in pepper (Kiewnick et al., 2009). Elucidation of the mechanisms involved in plant-nematode in- teractions, specifically resistance to $M$. incognita but susceptibility to $M$. enterolobii in 'UFRJ107(6)A3', is an important area for further research to increase the efficacy and durability of plant resistance.

As a starting point for understanding the mechanism of resistance in 'UFRJ107(6)A3', we compared the root penetration response of M. incognita J2s in 'UFRJ107(6)A3' with that of 'Datil'. The ability of the nematode to penetrate and migrate through the root cortex was affected by the host genotype (Table 3 ). Seven days after inoculation with $500 \mathrm{~J} 2 \mathrm{~s}$, an average of $102 \mathrm{~J} 2 \mathrm{~s}$ were observed in roots of 'Datil' plants, whereas no J2s were found in roots of five out of six plants of 'UFRJ107(6) A3'; the one plant had only one J2 inside the root (Table 3). During a single-pot choice test, when $M$. incognita-susceptible 'California Wonder' was planted together with 'UFRJ107(6)A3', $\approx 40 \mathrm{~J} 2 \mathrm{~s}$ had penetrated 
Table 4. Comparison of numbers of M. incognita race 3 second-stage juveniles (J2s) in roots of Capsicum annuum 'UFRJ107(6)A3' and 'California Wonder' after $7 \mathrm{~d}$ from inoculation with $500 \mathrm{~J} 2 \mathrm{~s}$ in a "choice test" where J2s had access to roots of either genotype.

\begin{tabular}{|c|c|c|c|c|}
\hline $\begin{array}{l}\text { Treatment }{ }^{2} \\
\text { Planted in different pots }\end{array}$ & Genotype $^{y}$ & Fresh root wt (gram) ${ }^{\mathrm{x}}$ & Number of J2s observed $^{x}$ & Number of J2s per gram of root $^{x}$ \\
\hline Planted together in one pot & $\begin{array}{c}\text { California Wonder } \\
\text { UFRJ107(6)A3 } \\
P\end{array}$ & $\begin{array}{l}1.04 \pm 0.3 \\
2.51 \pm 0.2\end{array}$ & $\begin{array}{c}40 \pm 1 \\
0 \\
* *\end{array}$ & $\begin{array}{c}48 \pm 16 \\
0 \\
* *\end{array}$ \\
\hline
\end{tabular}

${ }^{\mathrm{z}}$ Four- to five-leaf-stage pepper seedlings were transplanted to autoclaved sand and incubated in a growth chamber set at $30{ }^{\circ} \mathrm{C}$ with 12 -h photoperiod. A total of 12 plants were distributed to the following treatments, each with two replicate pots: two 'California Wonder' plants per pot; two 'UFRJ107(6)A3' plants per pot; and one of each genotype together in the same pot. After 1 week from transplanting, each of the two plants in the pot was inoculated with 250 24-h-old J2s suspended in $3 \mathrm{~mL}$ water and distributed into three holes made around the stem base of each plant, for a total of $500 \mathrm{~J} 2 \mathrm{~s}$ per pot.

${ }^{\mathrm{y}}$ 'UFRJ107(6)A3' is a $\mathrm{F}_{7}$ breeding line with the combined features of parent cultivars Jalapeño (for pungency) and Round of Hungary (for fruit color, high brix, and fleshy pericarp), as well as novel traits resulting from selections including broad-mite tolerance and adaptability to subtropical climate.

${ }^{\mathrm{x}}$ Data represent means $\pm \mathrm{SE}$ of two replicates. Statistical significance of the difference between the two genotypes in the number of J2s that penetrated the roots was tested using Student's $t$ test $(P \leq 0.05) .{ }^{*},{ }^{*}$ Significant at $P \leq 0.01$ or 0.001 , respectively.
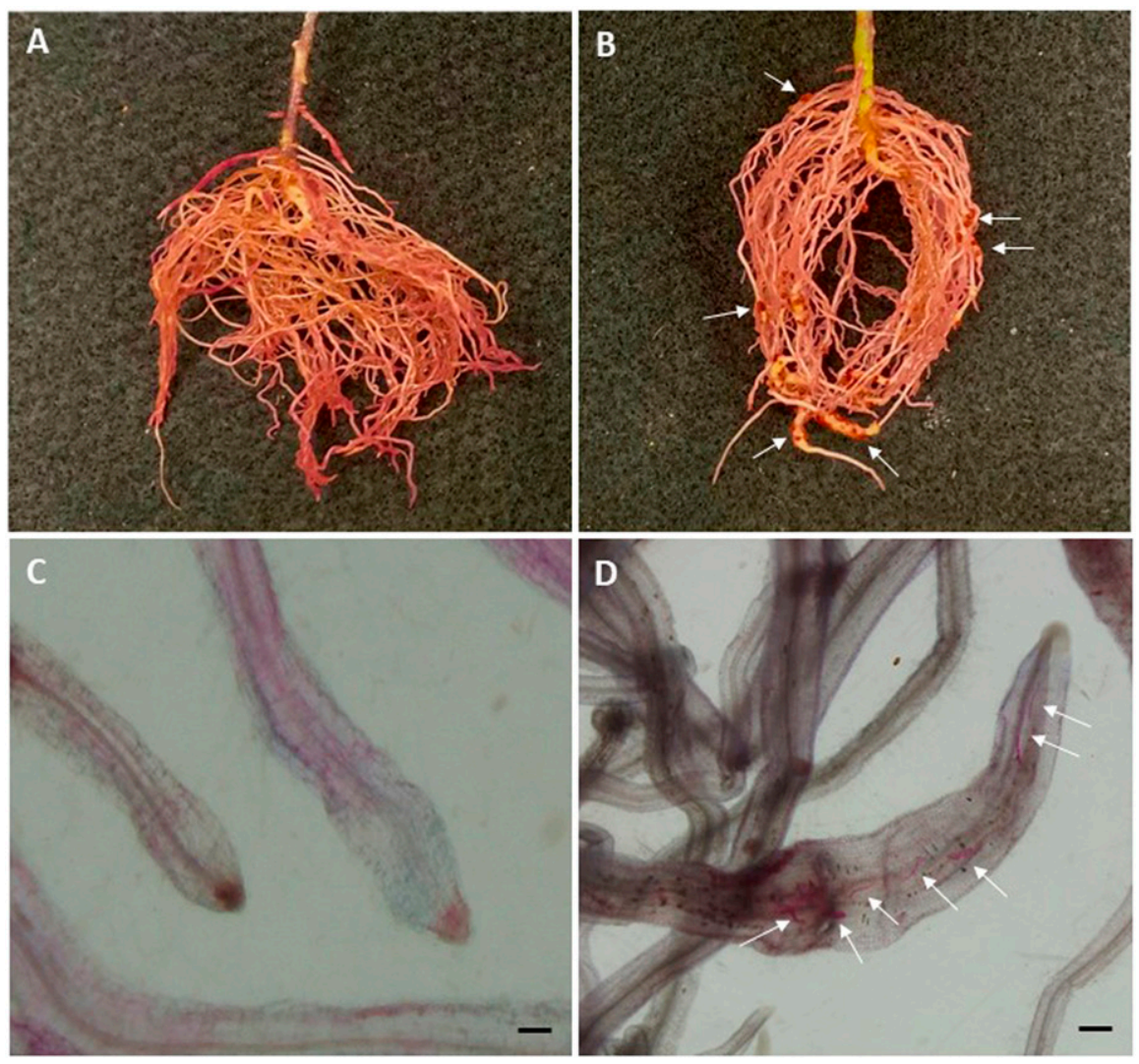

Fig. 2. Comparative differences in resistance to Meloidogyne incognita race 3 (Mi3) between 'UFRJ107(6) $\mathrm{A} 3$ ' and 'California Wonder'. Root systems stained with red food color $30 \mathrm{~d}$ after inoculation with $\mathrm{Mi3}$ second-stage juveniles (J2s) show the absence of egg masses in 'UFRJ107(6)A3' (A) and presence (indicated by white arrows) in 'California Wonder' (B). Acid fuchsin-stained roots of 'UFRJ107(6)A3' (C) and 'California Wonder' (D) show differences in the penetration response of Mi3 J2s (white arrows indicating J2 inside root tissue). Scale bars: $400 \mu \mathrm{m}$.

the roots of 'California Wonder', but none penetrated 'UFRJ107(6)A3' at $7 \mathrm{~d}$ after inoculation (Fig. 2, Table 4). Similar results were obtained when two of the same genotype were planted together in one pot because no nematodes penetrated the roots of 'UFRJ107(6)A3' (Table 4), confirming that resistance in 'UFRJ107(6)A3' is due to a lack of nematode penetration. This finding is consistent with those of previous reports that the nematode resistance mechanism in $C$. annuum genotypes 'HDA149' (Mel and Me3 genes), 'PM687' (Me3 gene), and
'CM334' (Me7 gene) acted at the early stages of root invasion that limited penetration or blocked migration of the RKN (BleveZacheo et al., 1998; Pegard et al., 2005). The nature of such an impediment in 'UFRJ107(6)A3' could be the presence of mechanical or biochemical barriers to RKN and needs further investigation.

The primary purpose of our research was to examine the reproductive potential and penetration ability of $M$. incognita race 3 on a breeding line and open-pollinated varieties that were not previously evaluated for resis- tance. We found that the reproductive potential of $M$. incognita race 3 on the advanced breeding line 'UFRJ107(6)A3' was remarkably less than that of 'Charleston Belle'. In addition, 'UFRJ107(6)A3' seemed to be able to prevent or limit the penetration and establishment of feeding sites and was broadly resistant against RKNs. During 7-d root penetration tests and choice tests, $M$. incognita race $3 \mathrm{~J} 2 \mathrm{~s}$ preferred the roots of susceptible varieties ('Datil' and 'California Wonder') over 'UFRJ107(6)A3'. Future research is required to test whether inherent mechanisms of RKN resistance in 'UFRJ107(6)A3' are similar to that conferred by the $M e 3$ gene in which the pepper line 'PM687' demonstrated immediate cellular necrosis in the root epidermis and inhibited penetration of $M$. incognita (Djian-Caporalino et al., 2001; Pegard et al., 2005). During Spring 2019, 'UFRJ107(6)A3' and two other breeding lines were grown in a field site infested with M. incognita. At the end of that season, roots of six plants per genotype were stained to evaluate egg masses. Although roots of two other lines contained egg masses, none was found in the roots of 'UFRJ107(6)A3' (data not shown). Altogether, 'UFRJ107(6)A3' has consistently shown a high degree of RKN resistance that would be useful for breeding programs and commercial pepper production. Its resistance is superior to that of the commercial cultivar Charleston Belle; therefore, it offers potential as a broad-spectrum RKN-resistant rootstock for grafting sweet bell peppers because the disease package in many of the modern hybrid pepper cultivars is lacking in RKN resistance.

\section{Literature Cited}

Aguiar, J.L., O. Bachie, and A. Ploeg. 2014. Response of resistant and susceptible bell pepper (Capsicum annuum) to a Southern California Meloidogyne incognita population from a commercial bell pepper field. J. Nematol. 46:346-351.

Biswas, T., Z. Guan, and F. Wu. 2017. An overview of the US bell pepper industry (FE1028). Gainesville: University of Florida Institute of Food and Agricultural Sciences. 4 Nov. 2018. $<$ https://edis.ifas.ufl.edu/fe1028>.

Bleve-Zacheo, T., M. Bongiovanni, M.T. Melillo, and P. Castagnone-Sereno. 1998. The pepper resistance genes $\mathrm{Mel}$ and $\mathrm{Me} 3$ induce 
differential penetration rates and temporal sequences of root cell ultrastructural changes upon nematode infection. Plant Sci. 133:79-90.

Bucki, P., I. Paran, R. Ozalvo, I. Iberkleid, L. Ganot, and S.B. Miyara. 2017. Pathogenic variability of Meloidogyne incognita occurring in pepper-production greenhouses in Israel toward $\mathrm{Mel}, \mathrm{Me} 3$ and $\mathrm{N}$ pepper resistance genes. Plant Dis. 101:1391-1401.

Byrd, D.W., Jr., T. Kirkpatrick, and K.R. Barker. 1983. An improved technique for clearing and staining plant tissues for detection of nematodes. J. Nematol. 15:142-143.

Castagnone-Sereno, P., M. Bongiovanni, and C. Djian-Caporalino. 2001. New data on the specificity of the root-knot nematode resistance genes $\mathrm{Mel}$ and $\mathrm{Me} 3$ in pepper. Plant Breed. 120:429-433.

Civerolo, E.L., S.K. Narang, R. Ross, K.W. Vick, and L. Greczy. 1993. Alternatives to methyl bromide: Assessment of research needs and priorities. Proc. USDA Wkshp. on Alternatives to Methyl Bromide, Arlington, VA, 29 June-1 July 1993. U.S. Dept. Agr., Washington, DC. 85 p.

Dickson, D.W., D. Huisingh, and J.N. Sasser. 1971. Dehydrogenase, acid and alkaline phosphatases, and esterases for chemotaxonomy of selected Meloidogyne, Ditylenchus, Heterodera, and Aphelenchus spp. J. Nematol. 3:1-16.

Djian-Caporalino, C., L. Pijarowski, A. Januel, V. Lefebvre, A. Daubèze, A. Palloix, A. Dalmasso, and P. Abad. 1999. Spectrum of resistance to root-knot nematodes and inheritance of heat-stable resistance in pepper (Capsicum annuum L.). Theor. Appl. Genet. 99:496-502.

Djian-Caporalino, C., L. Pijarowski, A. Fazari, M. Samson, L. Gaveau, C. O’Byrne, V. Lefebvre, C. Caranta, A. Palloix, and P. Abad. 2001. High-resolution genetic mapping of the pepper (Capsicum annuum L.) resistance loci Me3 and $\mathrm{Me} 4$ conferring heat-stable resistance to rootknot nematodes (Meloidogyne spp.). Theor. Appl. Genet. 103:592-600.

Fery, R.L. and J.A. Thies. 1997. Evaluation of Capsicum chinense Jacq. cultigens for resistance to the Southern root-knot nematode. HortScience 32:923-926.
Fery, R.L. and P.D. Dukes. 1996. The inheritance of resistance to the Southern root-knot nematode in 'Carolina Hot' cayenne pepper. J. Amer. Soc. Hort. Sci. 121:1024-1027.

Fery, R.L., P.D. Dukes, and J.A. Thies. 1998. 'Carolina Wonder' and 'Charleston Belle': Southern root-knot nematode-resistant bell peppers. HortScience 33:900-902.

Gisbert, C., C. Trujillo-Moya, P. Sánchez-Torres, A. Sifres, E. Sánchez-Castro, and F. Nuez. 2013. Resistance to pepper germplasm to Meloidogyne incognita. Ann. Appl. Biol. 162:110-118.

Hajihassani, A., W.B. Rutter, and X. Luo. 2019. Resistant pepper carrying $\mathrm{N}, \mathrm{Mel}$, and $\mathrm{Me} 3$ have different effects on penetration and reproduction of four major Meloidogyne species. J. Nematol. 51:1-9.

Hare, W.W. 1957. Inheritance of resistance to rootknot nematodes in pepper. Phytopathology 47:455-459.

Hendy, H., A. Dalmasso, and M.C. Cardin. 1985. Differences in resistant Capsicum annuum attacked by different Meloidogyne species. Nematologica 31:72-78.

Hussey, R.S. and K.R. Barker. 1973. A comparison of methods of collecting inocula of Meloidogyne spp., including a new technique. Plant Dis. Reptr. 57:1025-1028.

Kiewnick, S., M. Dessimoz, and L. Franck. 2009. Effects of the $M i-1$ and the $N$ root-knot nematode-resistance gene on infection and reproduction of Meloidogyne enterolobii on tomato and pepper cultivars. J. Nematol. 41:134 139.

Morris, K.A., D.B. Langston, R.F. Davis, J.P. Noe, D.W. Dickson, and P. Timper. 2016. Efficacy of various application methods of fluensulfone for managing root-knot nematodes in vegetables. J. Nematol. 48:65-71.

Oka, Y., S. Shuker, and N. Tkachi. 2012. Systemic nematicidal activity of fluensulfone against the root-knot nematode Meloidogyne incognita on pepper. Pest Manag. Sci. 68:268-275.

Pegard, A., G. Brizzard, A. Fazari, O. Soucaze, P. Abad, and C. Djian-Caporalino. 2005. Histological characterization of resistance to different root-knot nematode species related to phenolics accumulation in Capsicum annuum. Phytopathology 95:158-165.

Taylor, A.L. and J.N. Sasser. 1978. Biology, identification and control of root-knot nematodes (Meloidogyne species). Dept. Plant Pathol., North Carolina State Univ. and U.S. Agency for Intl. Dev., Raleigh, NC.

Thies, J.A. and R.L. Fery. 1998. Modified expression of the $N$ gene for Southern root-knot nematode resistance in pepper at high soil temperatures. J. Amer. Soc. Hort. Sci. 126:1012-1015.

Thies, J.A., D.W. Dickson, and R.L. Fery. 2008. Stability of resistance to root-knot nematodes in 'Charleston Belle' and 'Carolina Wonder' bell pepper in a sub-tropical environment. HortScience 43:188-190.

Thies, J.A., J.D. Mueller, and R.L. Fery. 1998. Use of a resistant pepper as a rotational crop to manage southern root-knot nematode. HortScience 33:716-718.

Thies, J.A. and R.L. Fery. 2000. Characterization of resistance conferred by the $N$ gene to Meloidogyne arenaria races 1 and 2, M. hapla, and $M$. javanica in two sets of isogenic lines of Capsicum annuum L. J. Amer. Soc. Hort. Sci. 125:71-75.

Thies, J.A. and R.L. Fery. 2002. Host plant resistance as an alternative to methyl bromide for managing Meloidogyne incognita in pepper. J. Nematol. 34:374-377.

Thies, J.A., S.B. Merrill, and E.L. Corley. 2002. Red food coloring stain: New, safer procedures for staining nematodes in roots and egg masses on root surfaces. J. Nematol. 34:179-181.

Thies, J.A. 2011. Virulence of Meloidogyne incognita to expression of $N$ gene in pepper. $\mathrm{J}$. Nematol. 43:90-94.

USDA-NASS. 2018. State agriculture overview for Florida. U.S. Dept. Agr. 3 Feb. 2020. <https:// www.nass.usda.gov/Quick_Stats/Ag_Overview/ stateOverview.php? state=FLORIDA $>$.

Wang, Y., Y. Yue, M.C. De New, and B. Rathinasabapathi. 2018. Stem and canopy architecture differences and their relationship to productivity in Capsicum annuum lines. Proc. Annu. Meet. Fla. State Hort. Soc. 131:121125. 